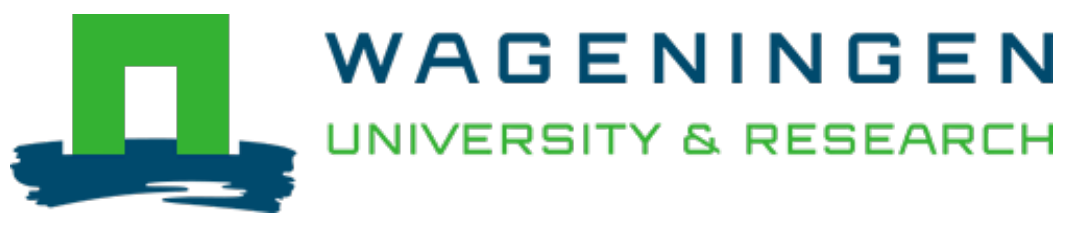

\title{
Feeding of lactic acid-fermented high nutrient density weaning formula in paediatric settings in Ghana and Nigeria: acceptance by mother and infant and performance during recovery from acute diarrhoea.
}

International Journal of Food Sciences and Nutrition

Mensah, P.; Ndiokwelu, C.I.; Uwaegbute, A.; Ablordey, A.; Boxtel, A.M.G.A. et al https://doi.org/10.3109/09637489509012567

This publication is made publicly available in the institutional repository of Wageningen University and Research, under the terms of article $25 \mathrm{fa}$ of the Dutch Copyright Act, also known as the Amendment Taverne. This has been done with explicit consent by the author.

Article 25 fa states that the author of a short scientific work funded either wholly or partially by Dutch public funds is entitled to make that work publicly available for no consideration following a reasonable period of time after the work was first published, provided that clear reference is made to the source of the first publication of the work.

This publication is distributed under The Association of Universities in the Netherlands (VSNU) 'Article $25 \mathrm{fa}$ implementation' project. In this project research outputs of researchers employed by Dutch Universities that comply with the legal requirements of Article $25 \mathrm{fa}$ of the Dutch Copyright Act are distributed online and free of cost or other barriers in institutional repositories. Research outputs are distributed six months after their first online publication in the original published version and with proper attribution to the source of the original publication.

You are permitted to download and use the publication for personal purposes. All rights remain with the author(s) and / or copyright owner(s) of this work. Any use of the publication or parts of it other than authorised under article $25 \mathrm{fa}$ of the Dutch Copyright act is prohibited. Wageningen University \& Research and the author(s) of this publication shall not be held responsible or liable for any damages resulting from your (re)use of this publication.

For questions regarding the public availability of this publication please contact openscience.library@,wur.nl 


\title{
Feeding of lactic acid-fermented high nutrient density weaning formula in paediatric settings in Ghana and Nigeria: acceptance by mother and infant and performance during recovery from acute diarrhoea
}

\author{
P. Mensah, ${ }^{1}$ C. I. Ndiokwelu, ${ }^{2}$ A. Uwaegbute, ${ }^{3}$ A. Ablordey, ${ }^{1}$ A. M. G. A. van Boxtel,${ }^{4}$ \\ C. Brinkman, ${ }^{4}$ M. J. R. Nout ${ }^{4}$ and P. O. Ngoddy ${ }^{5}$ \\ ${ }^{1}$ Noguchi Memorial Institute for Medical Research, Legon, Ghana; ${ }^{2}$ Department of Dietetics, University of \\ Nigeria Teaching Hospital, Emigu, Nigeria; ${ }^{3}$ Deparment of Home Science and Nutrition, University of \\ Nigeria, Nsukka, Nigeria; ${ }^{4}$ Department of Food Science, Agricultural University; Bomenweg 2, 6703 HD \\ Wageningen, The Netherlands and ${ }^{5}$ Department of Food Science and Techology, University of Nigeria, \\ Nsukka, Nigeria
}

\begin{abstract}
A period of acute diarrhoea in infants is often associated with anorexia and weight loss. Catch-up growth is, therefore, necessary and this depends very much on the type of food, in terms of nutrient density, protein quality and digestibility, given to the child. Fermented $(\mathrm{F})$ and non-fermented (NF) maize-soybean porridges of increased nutrient density were formulated and compared with traditionally fermented maize-only porridge $(P)$ for acceptability using mothers in peri-urban Ghana as well as urban Nigeria as subjects. Subsequently, infants hospitalised in paediatric wards for acute diarrhoea, from the same communities in both countries, were assigned randomly to one or other of the three porridges. Infant subjects in all cases fell within the ages of 6-15 months. Complementary to regular breast-feeding, infants could consume as much porridge as they wanted and their total daily consumption was interpreted as an indication of acceptance. Although mothers in both the environments of Ghana and Nigeria rated $\mathrm{P}$ as more acceptable than $\mathrm{F}$ and $\mathrm{NF}$, no significant difference was recorded in the quantitative intake by infants of the three formula groups. By adding enzyme-rich cereal malt flour (at the $1-5 \%$ level by weight) as a viscosity-thimning agent to $\mathrm{F}$ and NF porridges, it was possible to feed these porridges to infants at total solids concentration levels of $20-25 \%$ (wet basis) which is approximately double the solid matter content of the $\mathrm{P}$ porridge. Consequently, the daily nutrient intake by infants consuming $\mathrm{F}$ and NF porridges was considerably higher compared to the $\mathrm{P}$ porridge group. It is concluded that the concept of high nutrient density weaning foods is a feasible vehicle for an improvement of nutrient supply to infants.
\end{abstract}

\section{Introduction}

Acute diarrhoea in infants is often associated with a loss both in appetite and weight. Catchup growth following such episodes is essential. The type of food offered to the child for this purpose is critical. Six to 12 -month-old infants require, in addition to breast milk, supplementary food to meet their expanding nutritional requirements. In tropical areas, foods used for weaning usually consist of cereal-based gruels or porridges of low nutrient density. It is

Correspondence to M.J.R. Nout.

0963-7486/95/040353-10 @ 1995 Joumals Oxford Ltd 
difficult for infants suffering from diarrhoea, fed such diets, to catch-up rapidly. Indeed such infants, more often than not, become victims of nutritional deficiency diseases typified by protein energy malnutrition (PEM).

Black et al. (1984) and Barrel \& Rowland $(1979,1980)$ identified the high microbial load including pathogens of infant formula porridges as the primary causal agent of diarrhoeal infection in tropical climates. To address the problem of microbial quality of weaning formulas in tropical environments, Nout et al. (1989a, b) and Mensah et al. (1991a, b) demonstrated the efficacy of lactic acid fermentation as a route to microbiologically safer products. It is suggested that the by-products of fermentation can enhance the activity of infant gut microflora and, in the process, suppress colonisation by entero-pathogenic bacteria. Mensah et al. (1991b) list a range of nutritional and other benefits of lactic acid-fermented formulas that recommend them not only for infant weaning but, also in particular, for postdiarthoea feeding and rehabilitation. Nout et al. (1989a) and Nout $(1992,1993)$ developed and refined the method of inoculum enrichment ('back-slopping') for accelerated natural lactic acid fermentation of cereal-legume blends which, on reconstitution, yield acidic, low $\mathrm{pH}$ (4.5) porridges. In challenge tests, such weaning formulas have been shown to exhibit pronounced inhibitory properties against diarhoeal and other pathogens including Salmonella typhymurium, Staphylococcus aureus, Coliforms and members of the Enterobacteriaceae (Nout et al., 1989b). The purpose of the intercountry studies reported here was, therefore, to evaluate, through feeding trials in the contrasting environments of Ghana and Nigeria, (1) the acceplability of lactic acid-fermented and non-fermented maize-soya weaning formula porridges of high nutrient density by mothers and infants; and (2) to assess the performance of such porridges in terms of macronutrient intake during primary recuperative feeding of infants hospitalised with acute diarrhoea in paediatric ward settings.

\section{Materials and methods}

\section{Food preparation and analyses}

Three types of porridges were involved in this study, namely fermented (maize-soya blend plus malt-thinner) porridge $(F)$, non-fermented (maize-soya blend plus malt-thinner) porridge (NF) and traditionally fermented maize-only porridge $(\mathrm{P})$.

\section{Preparation of ingredients and formulations}

Maize meal. Whole maize seeds purchased locally in Accra, Ghana were cleaned and milled into a fine meal at a commercial custom mill. In Nigeria, clean maize seeds were milled into a fine meal after hydrothermal preconditioning and dehulling at the food processing pilot facilities of the University of Nigeria, Nsukka.

Soya bean meal. Clean dehulled (Nigeria) and undehulled (Ghana) soya beans were first toasted in a hot air oven at $180^{\circ} \mathrm{C}$ to reduce trypsin-inhibitor principles to an acceptable minimum and impart a light brownish colour and a mild toasted flavour. The toasted soya beans were subsequently ground into fine fullfat meal.

Malted cereal meal used in enzyme thinning of porridge. Maize (Ghana) and sorghum (Nigeria) grain seeds were cleaned and soaked overnight in excess tap water for $12-24 \mathrm{~h}$. The soaked seeds were germinated at room temperature (approximately $25^{\circ} \mathrm{C}$ ) in the dark. A regular regime of moisturisation was maintained to keep the sprouting seeds continuously wet. After 3 days of germination, the green malt of maize was dried in the sun over a period of 2 days to a moisture content below $10 \%$ wet basis. Sorghum green malt was dried at $55^{\circ} \mathrm{C}$ in a forced air drier over a period of 1-2h to a moisture content below $5 \%$ wet basis. The dried malt was either manually or mechanically derooted and cleaned prior to fine milling into a convenient flour for blending.

Maize-soya bean blend. Maize meal and soya bean meal were mixed in proportions of $4: 1$ (Ghana) and 7:3 (Nigeria) to obtain the formulation designated as NF in the country case studies.

Fermented maize-soya bean meal blend. Maize-soya bean blend as specified above was uniformly mixed with sufficient water to bring the mash moisture content to approx- 
imately $50 \%$ wet basis. The wet mass was put through the process of accelerated natural lactic acid fermentation using the method of back-slopping of Nout et al. (1989a) and Nout (1992). Anaerobic fermentation was conducted at $30^{\circ} \mathrm{C}$. Recycling of $10 \%$ of the preceding fermented batch into the next batch served as an enrichment inoculum. Using such enrichment starters, stable and reproducible products were harvested after $24-48 \mathrm{~h}$ of fermentation. In Ghana, the fermented mass was dried in the sun with regular periodic stirring over a period of 2 or more days to a moisture content below $10 \%$ wet basis. In Nigeria, drying was carried out in a cabinet dryer at an operating temperature of $55^{\circ} \mathrm{C}$ over a period of $7 \mathrm{~h}$ to a moisture content below 5\% wet basis. The dried fermented stream was then milled in a hammer or attrition mill to give the formula designated as $\mathrm{F}$.

Fermented maize meal (Ghana). Maize grain was washed and soaked in excess tap water for $48 \mathrm{~h}$ at room temperature. At the end of soaking, the grain was drained and wet milled in a plate mill into a fine wet mash. At a moisture content of approximately $50 \%$ wet basis the mash was fermented by anaerobic incubation for $48 \mathrm{~h}$ at room temperature. This fermented mash was then boiled with five parts water as indicated in Figure 1 under $P$.

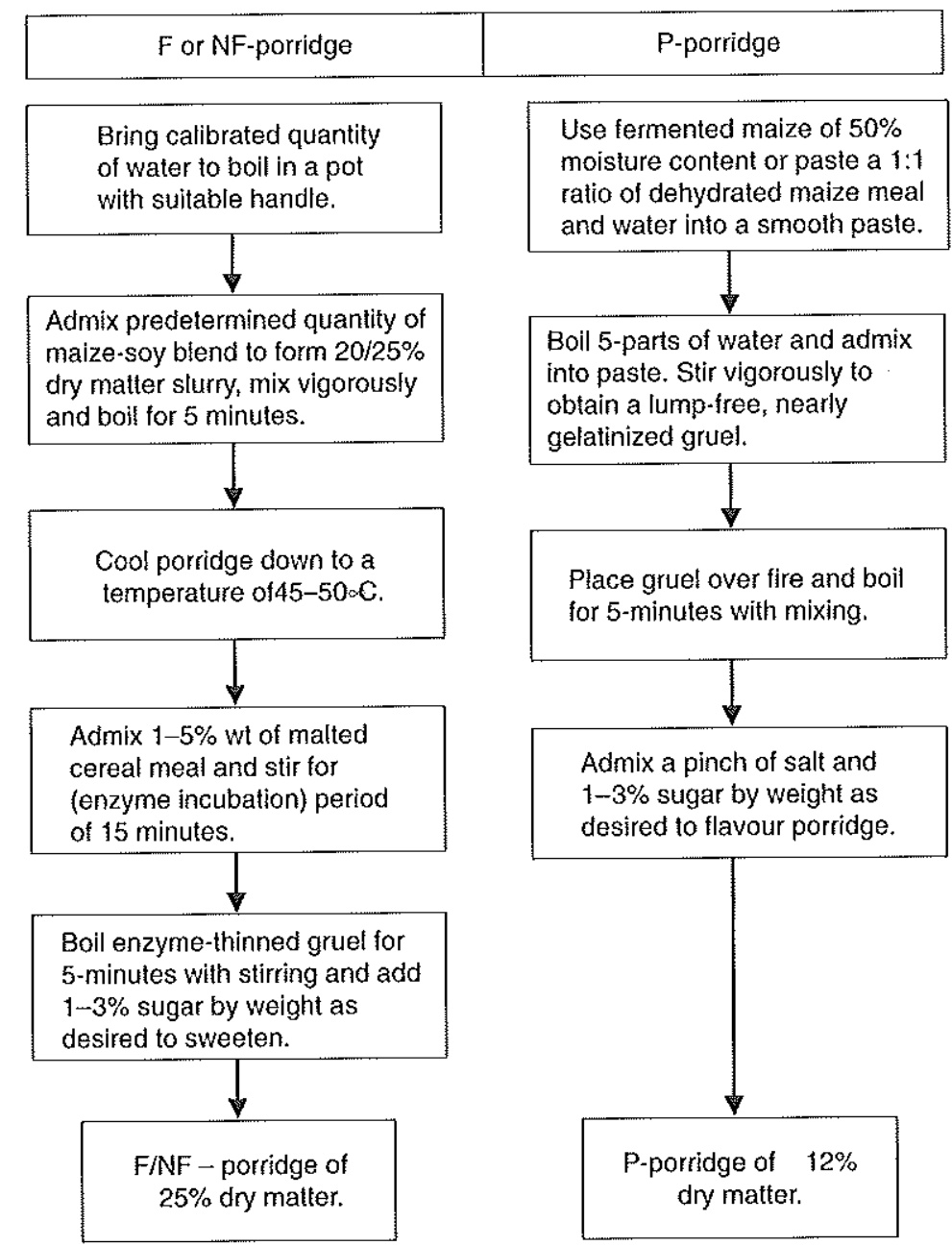

Figure 1. 
Fermented maize starch extract - 'Ogi' or 'Akamu' (Nigeria). Maize soaked in excess tap water was drained after $48 \mathrm{~h}$ and wet milled into a fine meal. The meal was wet sifted in a 40-mesh sieve to yield an impure maize starch extract. Following $36 \mathrm{~h}$ sedimentation and fermentation of the starch extract in a vessel, water was decanted, the starch recovered and dried in a cabinet drier at $55^{\circ} \mathrm{C}$ to a moisture content of below $5 \%$ wet basis. Fine milling of the dried extract gave a product traditionally called 'Ogi' in West Africa or 'Akamu' in the region and designated $\mathrm{P}$ in the Nigerian section of this study (Adeyemi \& Beckley, 1986). In Nigeria, $1.9 \%(w / w)$ palm oil, $2.5 \%$ (w/w) sucrose and $2.0 \%(\mathrm{w} / \mathrm{w})$ glucose were added to increase the energy content of $\mathrm{P}$.

Porridge preparation. Figure 1 profiles the scheme for porridge preparation used in the study for the three types of porridge under investigation.

\section{Chemical analysis}

In all cases, duplicate samples were analysed and the means of data were reported.

pH. A mixture of $10 \mathrm{~g}$ of dry sample and $90 \mathrm{ml}$ of distilled water was prepared in a high speed blender/homogeniser. The $\mathrm{pH}$ was determined by using a $\mathrm{pH}$ meter:

Dry matter: Dry matter was determined by weighing out a $1 \mathrm{~g}$ sample (to $1 \mathrm{mg}$ accuracy). The weighed sample was dried in a hot air convection oven $\left(105^{\circ} \mathrm{C}\right)$ over a period of $3 \mathrm{~h}$ with regular periodic weighing until the dry matter attained bone-dry condition that became weight-invariant in three successive weighings.

Crude protein. Organic nitrogen was determined by the micro-Kjeldahl method as described by Egan et al. (1981). Crude protein was calculated as $N \times 6.25$.

Ash, fat, fibre and minerals. Analyses for ash, fat, fibre and minerals were performed in accordance with the procedures of the UK Ministry of Agriculture, Fisheries and Food (1973) Mamual of Analytical Methods for Agricultural Materials.
Energy conversion coefficients employed. In all calculations involved in the analyses, the caloric energy content of plant proteins was approximated at $16.7 \mathrm{~kJ}$, that for fat was $37.6 \mathrm{~kJ}$ and that of granulated sugar was $16.7 \mathrm{~kJ}$.

\section{Microbiological analysis}

In all cases, duplicate samples were analysed and the means of data were reported. The products made in Ghana were tested as follows. Plate comts of microbial flora of samples were made after serial dilutions in peptone physiological salt solution (PPS). Plate count agar (Oxoid CM 325) was used for total counts, oxytetracycline glucose yeast extract agar (OGYE, Oxoid LM 545) was used for yeasts and moulds violet red bile glucose agar (VRBG) was used for Enterobacteriaceae and de Man Rogosa-Sharpe agar (MRS) was used for lactobacilli (Merck 10661).

\section{Evaluation of acceptability of porridges by mothers}

Selection of subjects. Antenatal and neonatal mothers (not related to the population of hospitalised infants) were engaged as subjects. A total of 40 mothers were involved in acceptance testing in the Maamobi Polyclinic in Accra Ghana. In Nigeria, the number of mothers involved was 20 at the University of Nigeria Teaching Hospital, Enugu.

Preparation of samples. The three types of porridges were prepared as described previously.

Preference test protocol. Paired preference and descriptive tests (Jellinek, 1985) were conducted in order to evaluate the acceptability of the porridges. Each subject received, on three separate occasions, a set of only two different porridge samples. Retasting was allowed. In Ghana, two simple responses were asked of the subject, namely (1) to describe the taste of each sample and (2) to indicate which sample was preferred. The coding of the total of six samples administered to each subject, as well as statistical evaluation (two-tailed $t$-test), was as recommended by Jellinek (1985). In Nigeria, subjects were asked to give their opinion on colour, flavour, texture and overall acceptability of the three porridges. Hedonic rating scales 
were converted to numerical scores, i.e. one point for 'most disliked' and seven points for 'most liked'. The unrelated $t$ '-test (Snedecor \& Cochran, 1980) was used to assess the significance of the data. Because some of the subjects were not literate, the questionnaires were completed by interviewers. Where necessary, questions were translated into local languages or dialects to ensure that the subjects understood them.

\section{Feeding during acute diarrhoea in hospital paediatric wards}

Selection of subjects. The subjects involved in this study consisted of male and female infants aged 6-15 months who were admitted and hospitalised for acute watery diarthoea as defined by De Mol et al. (1983), at the paediatric wards of the previously mentioned institutions.

Inclusion criteria for subjects engaged in the study were specified as follows: (1) the attendance of the patient and mother at the clinic leading to admission is voluntary and unsolicited, (2) the patient's age bracket is 6-15 months, (3) the patient must be already used to supplementary feeding, (4) the patient must satisfy all criteria for acute diarrhoea and (5) the onset of diarthoea prior to admission must not exceed 10 days.

Specific exclusion criteria for subjects were also defined as follows: (1) infants with persistent diarrhoea lasting more than 14 days, (2) infants with congenital or hereditary defects and (3) infants afflicted with chronic debilitating ailments.

Description of population. At admission, the mean recorded ages of the infants involved in the case studies were 10 (Ghana) and 8 months (Nigeria). Sixteen infants were involved in the Ghanaian study consisting of eight males and eight females. On the Nigerian side, there were 24 infants consisting of 13 males and 11 females. Most subjects (15 out of 16 in Ghana and 23 out of 24 in Nigeria) were still breast-fed with additional solid feeding at the time of the study. Using weight for height as a measure of nutritional status, approximately $25 \%$ of all subjects were slightly malnourished $(\mathrm{w} / \mathrm{h}=$ $70-80 \%$ ). Seventy-five per cent of the subjects were normal and above normal in respect of weight for height. The recorded age at which supplementary feeding was started varied from 2 weeks to 7 months. No national patterns were apparent.

In all but one (orphan) instances, it was the biological mother who brought the child to the hospital and attended to it. The recorded mean age of the mothers was 26 years. The mean number of children of each mother involved in the study was 3.0. The educational attainment of all the mothers was low. Most mothers worked as petty traders and shared, with their husbands, the financial burden of child up keep.

In general, the subjects had already received medication (in the nature of oral rehydration solids (ORS), paracetamol and/or chloroquine) prior to admission. In general, the medicationes prescribed and administered to all the infants was the same consisting of ORS, paracetamol and chloroquine. Less than $10 \%$ of the subjects had intravenous infusion. Less than $15 \%$ received prescribed doses of antibiotics.

Protocol of feeding. The three types of porridge (F, NF and $\mathrm{P}$ ) previously described, were prepared once (Nigeria) or three times (Ghana) daily and administered, for each patient, from a designated thermos flask. The subjects were designated as $\mathrm{F}$ group, NF group of $\mathrm{P}$ group, depending on the type of porridge fed the patient. The allocation of subjects to the feeding groups was at random. Each stbject was fed from his/her exclusive measuring cup. The porridge was weighed prior to and again after feeding. The amount consumed was recorded as the difference.

Feeding commenced immediately after initial correction of fluid balance and as soon as the child was able to take food by mouth. The experiment did not interfere with the administration of prescribed medication such as antibiotics. A little fruit was allowed. Mothers were encouraged to continue breast-feeding. Beyond these specific caveats, all macro nutrient feeding was excluded. Porridge was made available to the children in excess quantities for ad libitum consumption. The follow-up period in each case was continued until diarmoea ceased. This was defined as 3 consecutive days without diarthoea. Because it was not always possible to keep the infants in the hospital for an extended length of time, they were often discharged after only 1 or 2 days without diarrhoea. In Ghana, the child was returned for check-up 1 week after discharge. 
Evaluation of acceptability. For each type of porridge, the weight consumed voluntarily on a daily basis was recorded and interpreted as an indication of acceptance.

Evaluation of performance (nutrient intake). The daily intake of energy and protein for each individual was calculated on the basis of the weight of porridge consumed and its chemical composition. The unrelated $t^{\prime}$-test (Snedecor \& Cochran, 1980) was used to assess means and their respective standard deviations for statistical significance.

\section{Results and discussion}

\section{Chemical and microbiological properties of candidate porridges}

Tables 1-3 summarise the range of factorial attributes of porridges that were measured. Table $I$ shows that lactic acid fermentation of the maize-only and maize-soya blend at

Table 1. Dry matter and $\mathrm{pH}$ recorded during lactic acid fermentation of maize and maize-soya blends (Ghana)

\begin{tabular}{lcc}
\hline Te'st batch & $\begin{array}{c}\text { Dry matter } \\
\text { (\% Wet basis) }\end{array}$ & $\begin{array}{c}\text { PH affer } \\
\text { fermentation }\end{array}$ \\
\hline Maize ('P') & $49.4-51.3$ & $3.4-3.6$ (after $48 \mathrm{~h}$ ) \\
Maize-Soya ('F') & $58.3-60.0$ & $4.0-4.2$ (atter 24h) \\
\hline
\end{tabular}

$n=4$ samples; duplicate analyses.

Table 2. Microbial counts in the maize-soya blend ('F') alter 24 h fermentation, prior to porridge cooking

\begin{tabular}{llc}
\hline Media & \multicolumn{1}{c}{ Type of michoorgamism } & $\begin{array}{c}\text { Colony } \\
\text { forming } \\
\text { anits } \\
\left(\log _{H} N / g\right)\end{array}$ \\
\hline PCA & Total aerobic mesopfilic bacteria & $9.2-9.6$ \\
OGYE & Moulds & $<1.7$ \\
VRBG & Yeasts & $6.5-8.0$ \\
ERS & Lactic acid bacteria & $<1.7$ \\
& & $9.0-9.2$ \\
\hline
\end{tabular}

$n=4$ samples; duplicate antlyses.
Table 3. Microbial counts (CFU as $\log _{10} \mathrm{~N} / \mathrm{g}$ ) of three cooked porridges (F, NF and P) reatly for consumption

\begin{tabular}{lccc}
\hline $\begin{array}{c}\text { Potal aerobic } \\
\text { mesophilic } \\
\text { bacteria }\end{array}$ & $\begin{array}{c}\text { Entero- } \\
\text { bacteriaceate }\end{array}$ & $\begin{array}{c}\text { Iatic acid } \\
\text { bacteria }\end{array}$ \\
\hline $\mathrm{F}$ & $3.9-4.2$ & $<1.7$ & $3.9-4.1$ \\
$\mathrm{NF}$ & $3.7-5.5$ & $<1.7$ & $<2.7$ \\
$\mathrm{P}$ & $4.9-5.5$ & $<1.7$ & $4.8-5.1$ \\
\hline
\end{tabular}

$n=6$ samples; duplicate analyses.

$50-60^{\prime}$ moisture content wet basis resulted in an acidic $\mathrm{pH}(3.4-4.2)$ over a period of only $1-2$ days.

Tables 2 and 3 show that during lactic acid fermentation of maize-only meal or starchextract or maize-soyabean blend, the number of Enterobacteriaceae fell drastically while those of lactic acid bacteria and yeasts increased. Cooked fermented porridges ( $\mathrm{F}$ and P) still contained measurable numbers of lactic acid bacteria. This study confirms earlier reports to the effect that lactic acid fermentation imparts, in the porridge enviromment, attributes of robust safety and stability against infection by diarrhoeal and other pathogens (Mensah et al., 1991b; Svanberg et al., 1992; Nout, 1994).

Tables 4 and 5 profile the $\mathrm{pH}$, dry matter, energy, protein and mineral contents of all three porridge types involved in the study. $F$ and NF exhibit evident nutrient density superiority over $\mathrm{P}$. The energy content in Nigerian $P$ was closer to that of NF and $F$ due to the

Table 4 Chemical composition of porridges at administered in Ghanti ${ }^{a}$

\begin{tabular}{|c|c|c|c|c|}
\hline $\begin{array}{l}\text { Type of } \\
\text { porrilge }\end{array}$ & $p H$ & $\begin{array}{c}\text { Dry matter } \\
\text { (\% wet } \\
\text { basis) }\end{array}$ & $\begin{array}{c}\text { Energy' } \\
\left(k J / 100_{g}\right)\end{array}$ & $\begin{array}{c}\text { Cnude } \\
\text { protein } \\
(\mathrm{g} / 100 \mathrm{~g})\end{array}$ \\
\hline $\mathrm{F}$ & 4.20 & 22.10 & 416 & 3.06 \\
\hline $\mathrm{NF}$ & 6.20 & 22.80 & 430 & 3.14 \\
\hline$P$ & 3.75 & 9.50 & 168 & 1.04 \\
\hline
\end{tabular}

In Ghana, no attempt was made to stpplement with mineral mix or vitamin mix, sweeten with sugar or adjust energy' and viscosity by admixing fat. $a=6$ samples; duplicate analyses. 
addition of fat and sugars. In Ghana, no additions were made to $P$. In many instances, the protein concentration of $F$ and NF can be three to five times as much as that of $P$. The energy and dry matter concentrations are $1.5-2.5$ times as much as that of $P$.

Acceptability of porridges by mothers

Tables $6-8$ present the results of descriptive and paired-preference tests conducted with the mothers. Traditional fermented porridge $(P)$, either as whole-maize porridge in Ghana or as partial maize starch extract (Ogi or Akamu) in Nigeria, is preferred by mothers over both $\mathrm{F}$ and NF which are legume enriched. Although the actual feeding trials on the infants themselves suffering from acute diarrhoea (Table 9) may not mirror significant levels of differential aggregate intake of $F, N F$ and $P$ porridges, the mother's preference is an important force to reckon with when it comes to the choice of which particular formula is to be fed to an infant.

Preference for the traditional fermented cereal porridge is likely to derive from longestablished habits in both Ghana and Nigeria of feeding $\mathrm{P}$ to infants. Mothers who make the choice were themselves raised on this same formula. There is also a clear preference among both the Ghanaian and Nigerian subjects for NF over F stggesting that, by itself, the ingrained culture of feeding fermented gruel by mothers was not sufficient to give the advantage to $\mathrm{F}$. Comments by these mothers suggest that $\mathrm{F}$ is associated with a sharp after taste in the mouth that is particularly objectionable. Relative to NF, Table 8 shows that F was rated significantly lower in all four attributions assessed, namely colour, flavour, texture and acceptability.

Table 6. Description of porriclges by Ghanaian mothers

\begin{tabular}{lccc}
\hline Type of porridge & Good & Fair & Unucceptuble \\
\hline F & $4^{\text {a }}$ & 6 & 44 \\
NF & 29 & 6 & 19 \\
P & 53 & 2 & 0 \\
\hline
\end{tabular}

"Figtres represent total number of nothers who registered the response indicated about a particular product. 
Table 7. Preference tests of porridges by Ghanaian mothers

\begin{tabular}{lcr}
\hline Sample code score & Sample description & Preference \\
\hline F & Fermented maize-soya blend & $2.5^{\circ}$ \\
NF & Non-fenmented maize-soya blend & 15.0 \\
P & Traditional fermented maize only porridge & 21.5 \\
\hline
\end{tabular}

${ }^{a}$ Higher scores indicate preference; differences between aggregate preference scores are significant $(P<0.01)(n=40)$,

Feeding during acute diarhoea

Acceptability. Table 9 summarises the data collected from monitoring the intake of weaning food by the infants during admission. The mean daily food intake of porridges $\mathrm{F}, \mathrm{NF}$ and $\mathrm{P}$ recorded for diarrhoeal infants in both countries did not show significant differences although in Ghana there was a non-significant trend towards $\mathrm{F}>\mathrm{P}>\mathrm{NF}$. Considering that the weaning foods were taken voluntarily in addition to breast milk, this indicates that all three types of porridge were equally well accepted by the infants. Lorri (1993) appears to confirm the trend that the sour taste of lactic acid-fermented porridges can have an enhancing effect on the appetite of sick infants.

Performance. In all cases, recorded values of daily energy and protein intake were in the rank order of $F>N F>P$. This was also the case for daily intake on a body weight basis, except for the energy intake in Nigeria. This is explained by the enrichment of porridge $P$ with fat and sugars. These data show that compared to traditional-type porridges, the high-nutrient-dense porridges $\mathrm{F}$ and $\mathrm{NF}$ can serve as suitable vehicles for improved macronutrient supply. It should be noted that the total nutrient intakes as portrayed in Table 9 fall far short of stipulated (Cameron \& Hofvander, 1983; WHO, 1985) requirements. This means that even in the more concentrated form of $\mathrm{F}$ and $\mathrm{NF}$, at best only one-third of the energy and approximately one-half of the protein requirements can be supplied by what the sick child is able to consume. It is in this manner and for these reasons that for infants in the age-group of the study, cereal-based porridges should function in the role of supplements to breast milk in particular in the circumstances of acute diarrhoeal or other infections. According to Chandra (1982), some $50 \%$ of the caloric requirement of infants in this age group should be met from breast milk in nomal health. When famished by acute diarrhoea, the need for enhanced feeding by mobilising all available resources becomes even more compelling because the ideal therapy should provide sufficient nutrients to satisfy an increased demand induced by illness as well as the demand for catch-up (WHO, 1989). Given the earlier mentioned observation from the admission records of this study that most infant subjects were still breast-fed at the time they became involved in the study, it can be inferred that the

Table 8. Description of porridge quality attributes and acceptability by Nigerian mothers

\begin{tabular}{llll}
\hline Quality altribute & \multicolumn{1}{c}{ F } & $N F$ & $P$ \\
\hline Colour & & & $7.00 \pm 0.00 \mathrm{c}$ \\
Flavour & $4.25 \pm 0.55^{\mathrm{a}} \mathrm{a}^{\mathrm{b}}$ & $6.05 \pm 0.29 \mathrm{~b}$ & $6.45 \pm 0.21 \mathrm{e}$ \\
Texture & $2.75 \pm 0.49 \mathrm{~d}$ & $6.45 \pm 0.15 \mathrm{e}$ & $6.80 \pm 0.16 \mathrm{l}$ \\
Acceptability & $2.20 \pm 0.48 \mathrm{f}$ & $6.55 \pm 0.18 \mathrm{~g}$ & $6.10 \pm 0.49 \mathrm{j}$ \\
\hline
\end{tabular}

"Nean $\pm \mathrm{SD}(n=20$.).

hFor each attribute, scores with different labels ate significantly different $(i$-test; $P<0.01)$. 
general nutritional regime of the subjects during the study was satisfactory.

The experimental design did not allow any conclusions to be drawn regarding the effect of the different porridges on the rate of recovery from acute diarrhoea. The uncontrolled extent of breast-feeding, as well as the social factors affecting discharge from the hospital were major confounding factors. Generally, patients recovered sufficiently to be discharged in only 2-3 (Ghana) and 4-5 days (Nigeria). This time frame of recovery just did not allow a sufficient observational span to establish a convincing performance hierarchy of porridge type based on recovery rate as a sole criterion.

In real terms, considering the practical logistics of admission/discharge processes in African hospitals and dispensing with the fine technicalities of computed means across several subjects, Ghanaian infants were discharged after 3 days and Nigerian infants after 5 days of hospitalisation irrespective of the porridge type fed to the patients. It is not immediately clear from the data why Ghanaian infants were discharged so much faster. However, it is likely to be related to the local demand pressure for available hospital bed space and the commitment on the part of the hospital administration to satisfy as many urgent cases as possible. Beyond the crisis point of hospitalisation, patients are often discharged more in the acknowledgement of evidence of more urgent needs for the hospital beds they occupy and less as a reflection of an objective assessment of a patient's absolute need for the attainment of a state of complete recovery. In addition, Ghanaian mothers having to stay with their child at the hospital requested an early discharge so as to enable them to resume their domestic tasks. If the figures are considered against the perspective of these supervening exigencies, the need for much larger samples of contexts as well as patients and for more structured experimental settings than the present arrangements have allowed become apparent and compelling if the impact of the porridges on the state of health and nutrition needs to be studied.

Acknowledgement - The contribution of P. F. Nche during the manuscript preparation is gratefully acknowledged. 


\section{References}

Adeyeni IA \& Beckley O (1986): Elfect of period of maize fermentation and souring on chemical properties and amylograph pasting viscosity of ogi. J. Cereal Sci. 4, $353-360$

Barrel RAE \& Rowland MGM (1979): Infant food as a potential source of diamboeal illness in rural West Africa. Trams. R. Soc. Hygiene Trop. Med. 73, 85-90.

Barrel RAE \& Rowland MGM (1980): Commercial milk and indigenous weaning food in a rural West Africin environment: a bacterial perspective. J. Hygione Cambridge 84, 191-202.

Black RE, Brown KH \& Becker S (1984): Malnutrition is a determining factor in diarrheal duration, but not incidence, among young children in a longitudinal study in Rural Bangladesh. Am. J. Clim. Nutr. 37, 87-94.

Cameron H \& Hofvander Y (1983): Manual on Feeding Infonts and Young Children. New York: Oxford Medical Publications.

Chandra RK (1982): Physical growth of exclusively breastfed infants. Nutr. Res. 2, 275.

De Mol P, Brasseur P, Hemelhof W, Kalala T, Butzler JP \& Vis HL (1983): Enteropathogenic agents in children with diamoea in rural Zaire. Lancet i, 516-518.

Egan H, Kirl RS \& Sawyer R (1981): Pearson's Chemical Analysis of Foods. Essex: Longman Scientific and Technical Publishers.

Jellinek G (1985): Sensory Evaluation of Food and Practice. Chichester: Ellis Horwood.

Lorri WSM (1993): Nutritional and microbiological evaluation of fermented cereal weaning foods. PhD thesis, Chalmers University of Technology, Göteborg, Sweden.

Mensah P, Drasar BS, Harrison TJ \& Tomkins AM (1991a): Fernented cereal griels: towards a solution of the weanling's dilemma. Food Nutr: Bull. 13, 50-55.
Mensah P, Tomkins AM, Drasar BS \& Harison TJ (1991b): Antimicrobial effect of fermented Ghanaian maize dough. J. Appl. Bacteriol. 70, 203-210.

Ministry of Agriculture, Fisheries and Food (1973): The Analysis of Agricultural Materials. A Manual of the Analytical Methods Used by the Agricultaral Development and Advisory Senvice. London: Techsical Bulletin 27, Ministry of Agriculture, Fisheries and Food.

Nott MJR (1992): Accelerated natural lactic fermentation of cereal-based formulas at reduced water activity. $h t . J$. Food Microbiol. 16, 313-322.

Nout MJR (1993): Processed weaning foods for tropical climates. Int. J. Food Sci. Nutr: 43, 213-221.

Nout MJR (1994): Fenmented foods and food safety. Food Res. Imt. 27, 291-298.

Nout MJR, Rombouts FM \& Hautvasi GJ (1989a): Accelerated natural lactic fermentation of infant food formulations. Food Nutr. Bull. 11, 65-73.

Nout MJR, Rombouts FM \& Havelaar A (1989b): Effect of accelerated natural lactic fermentation of infant food ingredients on some pathogenic micro-organisms. $\mathrm{lth} . J$. Food Microbiol. 8, 351-361.

Snedecor GW \& Cochran WG (1980): Statistical Methods, 7th edn. Ames, IA: lowa State University Press.

Svanberg U, Sjogren E, Lori W, Svennerhom AM \& Kaijser B (1992): Inhibited growth of common enteropathogenic bacteria in lactic-fermented cereal grtels. Whd J. Microbiol. Biotechnol. 8, 601-606.

WHO (1985): Energy and Protein Requirements. Geneva: WHO Techinical Report Series No. 724

WHO (1989): The Treatment and Prevention of Acute Diarhoea. Practical Guidelines, 2nd edn. Geneva: WHO. 